\title{
Discurso de Instalación del Presidente de la Sociedad Chilena de Enfermedades Respiratorias por el bienio 2008-2009
}

\author{
Estimados amigos:
}

Ha llegado el momento de dirigirme a ustedes en mi calidad de presidente de nuestra Sociedad.

Cuando se me propuso que postulara a este cargo en las elecciones de directorio de 2006 y me dieron "diez minutos para que lo pensara”, me pregunté, y ... ¿Por qué yo? Soy un médico clínico que ha desarrollado su carrera y adquirido su experiencia en la atención de pacientes principalmente en el ámbito privado. Me formé como especialista, al amparo de mi tutor, el querido y siempre recordado Dr. Patricio González G. (Q.E.P.D.), en el Instituto Nacional del Tórax. No hice beca en países de habla inglesa, sino en la vecina República Argentina, en la Cátedra de Neumotisiología de la Universidad de Buenos Aires. Carezco de un listado de publicaciones y mi nombre no aparece en trabajos científicos de relevancia.

¿Qué cualidades podría tener yo para haber sido elegido para el cargo de presidente, hace dos años atrás? Supongo que pensaron que desde hace 10 años formo parte del directorio de la Sociedad Chilena de Enfermedades Respiratorias en el que he desempeñado diferentes cargos (director, tesorero y vicepresidente), que soy una persona conciliadora, responsable, comprometida con lo que se propone, metódica y obsesiva y por sobre todas las cosas, amo mi profesión, amo mi especialidad y amo a esta Sociedad para la cual ofrezco mis mejores esfuerzos y talentos, y desde este puesto contribuir, como brillantemente lo han hecho mis ilustres antecesores, a su engrandecimiento y seguir contribuyendo en el estudio, prevención y manejo de las enfermedades respiratorias en nuestro país.

Para lograr estos últimos objetivos pretendo:

1. Incentivar a los socios a presentar proyectos de investigación tanto individuales como multicéntricos.

2. Apoyar a través de subsidios o becas, la participación de socios en actividades de educación médica continua.

3. Continuar la senda de administraciones anteriores, en incentivar y promover activamente una mayor integración de la comunidad pediátrica, ya que juntos le damos la fuerza, empuje y razón de ser de la Sociedad.

4. Buscar los medios y recursos para que las distintas comisiones de nuestra Sociedad, desarrollen planes de trabajo de manera que sean ellas las que nos guíen hacia las áreas de interés a enfatizar en las distintas actividades científicas de la Sociedad.

5. Promover las actividades regionales que se están realizando con señalado éxito, y crear nuevos espacios de participación de las regiones en actividades científicas que resalten su realidad local.

6. Hacer todos los esfuerzos posibles en crear un "mes de los pulmones", dedicado a la difusión, conocimiento y prevención de las enfermedades respiratorias a nivel nacional, actividad que ya tuvo su debut con la "semana del asma" realizada en Osorno, entusiastamente dirigida por el Dr. Edgardo Grob y el equipo que él dirige.

7. Mantener y en lo posible aumentar el abanico de publicaciones científicas en el MD Consult y a su vez promover entre los socios el uso de este invaluable medio de actualización de conocimiento. 
8. Invitarlos a participar activamente en cada una de las actividades que ya están siendo programadas para los próximos dos años, ya que ellas nos permiten compartir conocimientos, pero por sobre todo incentivar el compañerismo y la amistad, para lo cual ya se están organizando programas recreativos que nos permita disponer de más tiempo para el esparcimiento.

Finalmente, me sentiría muy satisfecho si en dos años más el Directorio que tengo el honor de presidir, ha podido alcanzar estas metas y formar entre mis distinguidos predecesores un Comité de Past-presidents, que indudablemente acumulará la experiencia de los años pasados y será fuente de inspiración y consejo para quienes le corresponda la responsabilidad de dirigir los destinos de mi querida Sociedad Chilena de Enfermedades Respiratorias, que ahora me honra como su Presidente.

Un abrazo para cada uno de ustedes, con mis sentimientos de aprecio y alta estima.

Dr. Fernando Rivas Burattini

Presidente, Sociedad Chilena de Enfermedades Respiratorias 